\title{
AC 2009-1628: DO INTROVERTS PERFORM BETTER IN COMPUTER PROGRAMMING COURSES?
}

\section{Kyle Lutes, Purdue University}

Kyle Lutes is an Associate Professor for the Department of Computer \& Information Technology (CIT) at Purdue University. Kyle joined the department in 1998 and is the chair of the department's software development curriculum. His teaching and scholarly interests cover a broad range of software development areas including software applications for mobile devices, data-centered application development, and software entrepreneurialism. He has authored/co-authored numerous papers and two college textbooks on various software development-related topics. Prior to his current appointment at Purdue, Kyle worked for 16 years as a software engineer and developed systems for such industries as banking, telecommunications, publishing, healthcare, athletic recruiting, retail, and pharmaceutical sales.

\section{Alka Harriger, Purdue University}

Alka Harriger joined the faculty of the Computer and Information Technology Department (CIT) in 1982 and is currently a Professor of CIT and Assistant Department Head. Professor Harriger's current interests include reducing the IT gender gap, web application development, and service learning. Since January 2008, she has been leading the NSF-ITEST SPIRIT project that seeks to rekindle enthusiasm for information technology disciplines as a career choice among high school students, especially young women.

\section{Jack Purdum, Purdue University}

Dr. Jack Purdum has authored over 13 programming texts, numerous magazine articles and technical papers, and has over 25 years of teaching experience. He served as the director of development for a software company that produced programming tools, compilers, and statistical software for PC's coupled wit almost 30 years of consulting experience. 


\title{
Do Introverts Perform Better in Computer Programming Courses?
}

\begin{abstract}
Any educator who has taught computer programming courses knows that some students have a very difficult time learning the basic concepts of computer programming. There often is no middle ground with the grades in these courses. Once a student catches on to the basic concepts, he or she has an easy time with the rest of the course. However, some students of high intelligence and who receive high marks in non-programming courses seem to continually struggle through these courses. Recently while reading about the personality traits of introverts, we noticed that many qualities attributed to introverts also match the traits found in great computer programmers. For example, attention to detail, the ability to concentrate for long periods of time and good logical thinking skills are published qualities found in both introverts and successful software developers. To see if we could find any correlation with a student's tendency towards introversion or extroversion, and potential success in our computer programming courses, we performed a study during the Fall 2008 and Spring 2009 semesters. We gave all students enrolled in each of the five programming courses we offered these semesters a short personality trait test and then compared their tendencies towards introversion or extroversion with the letter grade they received at the end of the course. We anticipated finding higher grades among those students classified as introverts and lower grades among those students classified as extroverts. Additionally, we anticipated finding a higher number of introverts enrolled in our upper division programming courses because these courses are elective. In this paper we will explore the traits found in introverts and programmers in more detail, discuss the personality test we used, and present our complete findings.
\end{abstract}

\section{Introduction}

As educators who primarily teach software development courses, we know that some students have a very difficult time learning the fundamentals of computer programming. There often is no middle ground with the grades in these introductory courses. Students who catch on to the basic concepts of computer programming have an easy time with the remainder of the course work. The students who don't grasp the fundamentals struggle the entire term. Because of their failing grade and/or lack of knowledge, these students must retake the course or may even switch majors.

Failure to earn a passing grade in a college course is often directly attributable to the effort put forth by the student. However, the authors of this study have each known many students of seemingly high intelligence and who normally earn high marks in non-programming courses, struggle with our computer programming courses. For example, one student who graduated as the high school valedictorian could not pass our introductory programming course on the first try.

During a counseling session with one student who was failing our introductory programming course, the lead author of this study discussed the student's personality traits with him. This conversation was prompted by the author having just finished reading "The Introvert Advantage 
- How to Thrive in an Extrovert World" by Marti Olsen Laney ${ }^{1}$. While reading Laney's book, the author discovered that he had many of the traits found in introverts. For example, paying attention to detail, the ability to concentrate for long periods of time, and good logical thinking skills are published qualities found in introverts that the author also possessed. This led him to question if most good software developers also tended to be introverted, or conversely, if people who were very extroverted generally were not good at computer programming.

During this counseling session, it became clear the student was indeed very extroverted. He stated he did not like to sit down in front of a computer for very long and was easily distracted. Additionally, he enjoyed his part-time job as a bartender because of the interaction he had with so many different people. The student was relieved to learn that perhaps it was his personality traits that were making learning the course material difficult and not his lack of intelligence.

After this experience, the subject of introversion and its relationship to programming success became a discussion topic among the core programming faculty. The other faculty also identified themselves as introverts. The team began investigating the literature for any evidence that could validate or disprove the team's premise that introverts may be better suited to programming.

\section{Traits Common to Introverts and Software Developers}

In her book, Laney works to change the incorrectly held belief by many that introverts are shy, reclusive, social misfits who dislike being around people. Instead, she offers this simple distinction: people who tend to be more introverted focus inward to gain energy, and people who tend towards extroversion focus outward to gain energy. Other observations Laney makes about introverts that are relative to this paper include:

- Introverts are energized by the internal world - by ideas, impressions, and emotions.

- Introverts do better on tasks that require careful attention and notice details many people miss.

- Introverts enjoy complexity when they can focus on one or two areas, without pressure.

- Introverts like to have large uninterrupted time periods when working on projects.

- Introverts are creative and/or imaginative.

- Introverts are often absorbed in thought.

- Introverts listen before they talk.

These observations about introverts can easily be seen as observations that might also be made about people who excel at computer programming. In his article "10 traits to look for when you're hiring a programmer", James includes these traits in his list ${ }^{2}$ :

- Curiosity

- Clear thinking skills

- Top flight reading speed and comprehension

- Attention to detail

- Quick learner outside of programming

- Self-learning skills

- Passion 
- Good communication skills

The traits found in both lists have many similarities. In fact, it is known that introverts make good computer programmers in the professional work force. In the article "Best Jobs for Introverts" published by the Washington Post, Computer Software Engineer (Applications) and Computer Software Engineer (Systems Software) are listed as the number \#1 and \#2 jobs ${ }^{3}$. Additionally, the article "The 25 Best-Paying Jobs for Introverts" ranks Computer Software Engineer as \#6, Computer Systems Analysts as \#18, and Computer Programmers as \#25 ${ }^{4}$.

Given the known correlation between introversion and computer programming skills, we were curious to know if a similar correlation could be found with college students. In other words, do introverted students perform well in their computer programming courses? The remainder of this paper reports the results from our study which was designed to answer this question.

\section{Study Design}

There are a number of personality tests available commercially, both online and in printed books. When designing the study we had several issues to address regarding what personality test was best for our study:

- While most personality tests address multiple characteristics, our focus was on developing/using a test to identify extroversion/introversion.

- We had no funding for this study, so public/free tests were sought.

- The questions should not appear to have a bias for or against introversion.

- The surveys would have to be administered in several classes without disrupting the course schedule too much.

- The surveys should be short enough that the students did not think of it as a chore to complete and the instructors did not think of it as a burden that took too much class time.

- The surveys should be long enough to be meaningful.

Most of the tests available in the literature were very lengthy ${ }^{5,6,7,8}$, so they were eliminated from consideration for our study. An abridged extroversion test with ten questions ${ }^{9}$ was found; however, nearly all of the questions were biased in favor of extroversion. For the statistical analysis, the team created a simple test that was derived from an introvert/extrovert questionnaire designed by Dr. John W. Pelley at Texas Tech University ${ }^{10}$. The lead investigator contacted Dr. Pelley and received his permission to use his work in the study. Appendix A shows the test that was ultimately given to the students. The questionnaire has seven statements designed to reflect either an introvert or extrovert personality. Students either agree or disagree with the statement yielding a set of binary responses.

Once the actual test was decided, the team began developing the study protocol for approval from the Institutional Review Board (IRB) to conduct the pilot study. Because some people may assume that introversion carries a negative connotation, the test was labeled, "Study Habits of Students in Computer Programming Courses." 


\section{The Data}

After we received IRB approval, we administered the tests to the student in all our programming courses offered in two consecutive semesters. At the conclusion of each semester, final course grades were provided by the course instructors. These course grades were then compared to the results of the personality test to determine levels of correlation between introversion and success in programming courses. Table 1 summarizes the courses in which the personality test was administered.

Table 1: Courses in which personality tests were administered

\begin{tabular}{|l|l|l|r|}
\hline $\begin{array}{c}\text { Course } \\
\text { Code }\end{array}$ & \multicolumn{1}{|c|}{ Description } & $\begin{array}{c}\text { Required or } \\
\text { Elective }\end{array}$ & $\begin{array}{c}\# \\
\text { Responses }\end{array}$ \\
\hline CIT 155 & Introductory course in OOP using C\# & Required & 102 \\
\hline CIT 255 & Web application development using ASP.NET and C\# & Required & 101 \\
\hline CIT 295 & Advanced OOP using Java & Required & 88 \\
\hline CIT 355 & Software development for mobile computing devices & Elective & 38 \\
\hline CIT 450 & Enterprise application development & Elective & 12 \\
\hline
\end{tabular}

The first column in Table 1 is the course identification number for each class. The second column provides a brief description of the course topics. The third column indicates if all students were required to take the course or if they elected to take the course. The fourth column lists the number of students who completed our test (and is also the sample size in subsequent statistics). The first three courses listed in the table are required of all students majoring in the CIT program. These courses are typically taken during the freshman and sophomore years. The remaining two classes are electives, and are normally selected by students who are concentrating in software development (i.e., programming). Because the latter two are electives, they tend to have smaller enrollments than the first three courses. Also, CIT 450 is only offered one semester per year, hence its small sample size.

At the end of the second semester, the student responses were collated and entered into a data file along with their identification number and the corresponding grade earned in the course. Student grades, which are alpha values, were recorded as numeric values as shown in Table 2.

Table 2: Grade Coding

\begin{tabular}{|c|c|}
\hline Course Grade & Numeric Value \\
\hline A & 95 \\
\hline B & 85 \\
\hline C & 75 \\
\hline D & 65 \\
\hline F & 55 \\
\hline
\end{tabular}

Along with the students' identification numbers and course grade, the data file recorded the raw survey response data, the number of responses that are identified as reflecting introvert personalities, and the percent of the total responses that were introvert responses. 
Table 3 shows the summary statistics taken from the raw data files. The mean reflects the average number of responses that were "introvert" in nature. For example, in the CIT 155 class, the 102 students averaged about three introvert-based answers from the seven statements posed on the questionnaire. (We used the numeric count values rather than the percentages since the raw data are not subject to rounding errors like the percentage figures might be.)

The standard deviation reflects the dispersion within the data. In simple terms, the standard deviation indicates the degree to which the mean truly reflects the underlying data. For example, if every student had exactly three introvert responses, the standard deviation would be zero and the mean would be a perfect predictor of the underlying data. As can be seen in Table 3, the standard deviation values suggest there is a fair amount of dispersion in the raw data.

Table 3: Summary Statistics

\begin{tabular}{|l|l|l|l|l|l|}
\hline & IT 155 & IT 255 & IT 295 & IT 355 & IT 450 \\
\hline Mean & 3.28846 & 2.96039 & 3.20224 & 3.07894 & 2.33333 \\
\hline Standard Deviation & 1.39814 & 1.43472 & 1.47077 & 1.28150 & 1.55699 \\
\hline Sample Size & 102 & 101 & 88 & 38 & 12 \\
\hline
\end{tabular}

\section{Correlation Results}

The questionnaire attempts to measure whether there is a correlation between students' introvert traits and their course grades. The theory is that highly introverted students would tend to get higher grades in these programming courses. That is, the higher the number of introverted statements the student selected on the questionnaire, the higher the associated course grade for that student.

To test the relationship, a correlation analysis was run on the data between the number of introvert statements the students selected relative to their course grades. The results of the correlation analysis are shown in Table 4.

Table 4: Correlation Coefficients

\begin{tabular}{|l|c|}
\hline Course & Correlation Coefficient \\
\hline IT 155 & .20583523 \\
\hline IT 255 & .09524649 \\
\hline IT 295 & .09744170 \\
\hline IT 355 & -.06036596 \\
\hline IT 450 & .27669930 \\
\hline
\end{tabular}

The first thing to notice is the weak correlations in general. If grades and the number of introvert responses were perfectly correlated in a positive sense, the correlation coefficient (column 2 in Table 4) would be 1.000. If the correlation was perfectly inverse (i.e., introverted students get low grades), the correlation coefficient would be -1.000 . As can be seen in Table 4, all of the correlations are very weak. Interestingly, the correlation coefficient for the mobile computing 
class (CIT 355) is inversely correlated, suggesting that introverted students tend to get lower grades in the mobile programming course!

If the hypothesis under consideration is true, then we would expect to find more introverts in the second course and, concomitantly, a higher correlation coefficient for CIT 255 than for CIT 155. That is, the first programming course (CIT 155) might serve to discourage extroverted students from progressing into the second programming course (CIT 255). However, the exact opposite appears to be true: the correlation coefficient drops by more than half in the second programming course. The correlation coefficient remains about the same for the third programming course (CIT 295).

Recall that the first three courses are required and the last two are electives that are normally taken only by students who are following the software development track. The coefficients for the two courses are noticeably different than that for the required courses, especially given the sign change for CIT 355.

The hypothesis under consideration is that students have a tendency toward introversion will perform well in our computer programming courses. The concept of a "good programmer" in a college course is measured by the student's grade in the course. The data used to reflect an introvert personality is the number of introvert responses the student made on the questionnaire. Those two variables are then tested using correlation analysis to assess the strength of the relationship between the two variables. The statistics suggest that the relationship between a student's introverted tendencies and his or her grade in our computer programming courses is, at best, very tenuous. Indeed, it appears that there is substantially less than a 50-50 chance that students' success in a course can be predicted by their introvert tendencies.

\section{Conclusion}

The results of the study were somewhat surprising based on the authors' personal traits and programming experiences coupled with recommendations in the literature that introverts should consider computing careers. Perhaps the short length of the quiz may have been insufficient to accurately identify introvert tendency. Nonetheless, programming today is very different from programming in the 1980s. People no longer have to wait hours for an operator to run their jobs simply to find any compile errors. Today's integrated development environments with intellisense editors seem to reduce the dependency on attention to detail and may be contributing to a reduced performance difference between introverts and extroverts. Furthermore, college students today are arriving with higher computer literacy and proficiency in using social networks to abet problem-solving. All of these environmental changes may have equalized the opportunities for success in a programming course for introverts and extroverts alike. 


\section{Bibliography}

1. Laney, M., (February 1, 2002), "The Introvert Advantage - How to Thrive in an Extrovert World", Workman Publishing Company (ISBN: 978-0761123699)

2. James, J., (March 5, 2008), "10 traits to look for when you're hiring a programmer", TechRepublic, retrieved February 2009 from http://blogs.techrepublic.com.com/10things/?p=319

3. JIST Publishing, (May 18, 2008), "Best Jobs for Introverts", WashingtonPost.com, retrieved February 2009 from http://www.washingtonpost.com/wp-dyn/content/article/2008/05/17/AR2008051700979_pf.html

4. JIST Publishing, (2008), "The 25 Best-Paying Jobs for Introverts", retrieved February 2009 from http://www.jist.com/shop/web/best-jobs-lists/the-25-best-paying-jobs-for-introverts

5. John, O. P. and Srivastava, S. (March 1999), "The Big-Five trait taxonomy: History, measurement, and theoretical perspectives" In L. Pervin and O.P. John (Eds.), Handbook of personality: Theory and research (2nd ed.). New York: Guilford

6. Bromberg, P. A., (December 10, 2006), "Jungian type test for programmers", retrieved September 2008 from http://www.eggheadcafe.com/articles/mb/default.asp

7. McCaulley, M.H. and Martin, C.R., (1995), "Career Assessment and the Myers-Briggs Type Indicator", Journal of Career Assessment, 3(2), 219-239.

8. Wikipedia, (December 13, 2008). "Keirsey Temperament Sorter.", retrieved February 2009 from http://en.wikipedia.org/wiki/Keirsey_Temperament_Sorter

9. Shepherd, P., (2003), "Know your own mind: Personality questionnaire", retrieved Februrary 2009 from http://www.trans4mind.com/questionnaire/questionnaire.pdf

10. Pelley, J., "The Success Types Learning Style Type Indicator", retrieved September 2007 from http://www.ttuhsc.edu/SOM/Success/LSTI.htm 


\section{Appendix A - Study Habits of Students in Computer Programming Courses}

Overview

Several faculty members are researching the study habits of students in programming courses to see if these study habits have any correlation with success in programming courses. Please know your name, ID, and your answers to the questions will be kept confidential. By providing your honest answer to each of the seven questions below, you can help the department improve the quality of its programming courses, and you will be awarded five quiz points.

Question \#1

A) I study best with other people.

B) I study best by myself.

Question \#2

A) When I study with other people, I get the most out of listening to what others have to say.

B) When I study with other people, I get the most out of expressing my thoughts.

Question \#3

A) When I study with other people, I get the most out of thinking things through before I say them.

B) When I study with other people, I get the most out of quick, trial-and-error thinking.

Question \#4

A) I prefer to start my learning by doing something active and then considering the results later.

B) I prefer to start my learning by considering something thoroughly and then doing something active with it later.

Question \#5

A) I can study for very long stretches and interruptions are not welcome.

B) I need frequent breaks when I study and interruptions don't bother me.

Question \#6

A) I prefer to describe what I know.

B) I prefer to demonstrate what I know.

Question \#7

A) I like to know what other people expect of me.

B) I like to set my own standards for my learning. 